This document was prepared in conjunction with work accomplished under Contract No. DE-AC09-96SR18500 with the U. S. Department of Energy.

\title{
DISCLAIMER
}

This report was prepared as an account of work sponsored by an agency of the United States Government. Neither the United States Government nor any agency thereof, nor any of their employees, makes any warranty, express or implied, or assumes any legal liability or responsibility for the accuracy, completeness, or usefulness of any information, apparatus, product or process disclosed, or represents that its use would not infringe privately owned rights. Reference herein to any specific commercial product, process or service by trade name, trademark, manufacturer, or otherwise does not necessarily constitute or imply its endorsement, recommendation, or favoring by the United States Government or any agency thereof. The views and opinions of authors expressed herein do not necessarily state or reflect those of the United States Government or any agency thereof.

This report has been reproduced directly from the best available copy.

Available for sale to the public, in paper, from: U.S. Department of Commerce, National Technical Information Service, 5285 Port Royal Road, Springfield, VA 22161, phone: (800) 553-6847, fax: (703) 605-6900

email: orders@ntis.fedworld.gov

online ordering: http://www.ntis.gov/help/index.asp

Available electronically at http://www.osti.gov/bridge

Available for a processing fee to U.S. Department of Energy and its contractors, in paper, from: U.S. Department of Energy, Office of Scientific and Technical Information, P.O. Box 62, Oak Ridge, TN 37831-0062,

phone: (865)576-8401,

fax: (865)576-5728

email: $\underline{\text { reports@ adonis.osti.gov }}$ 


\section{Application of Material Characterization Techniques to Electrical Forensic Analysis}

\author{
T. David Mills, P.E. \\ Senior Member, IEEE \\ Bechtel Savannah River, Inc. \\ Savannah River Site \\ Aiken, SC 29808 \\ U.S.A. \\ 803-952-9011 \\ 803-952-9220 \\ d.mills@ieee.org
}

\author{
Richard S. Hoskins \\ Westinghouse Savannah River \\ Company \\ Savannah River Site \\ Aiken, SC 29808 \\ U.S.A. \\ 803-952-8973 \\ 803-952-9220 \\ richard.hoskins@srs.gov
}

\author{
Marie S. Nemier \\ Member, IEEE \\ Trentec, Inc. \\ 4600 East Tech Drive \\ Cincinnati, Ohio 45245 \\ U.S.A \\ 513-528-7900 \\ 513-528-9292 \\ mnemier@trentec.com
}

\begin{abstract}
The application of forensic science techniques to electrical equipment failure investigation has not been widely documented in the engineering world. This paper is intended to share an example of using material characterization techniques to support an initial cause determination of an electrical component "failure" event. The resulting conclusion supported the initial cause determination and ruled out the possibility of design deficiencies. Thus, the qualification testing of the equipment was allowed to continue to successful completion.
\end{abstract}

Index Terms - Forensics, seismic qualification, material characterization, scanning electron microscope, SEM, uninterruptible power supply, UPS.

\section{INTRODUCTION}

Electrical equipment often needs to be seismically tested and qualified in order to be placed into nuclear service. Typically, the methods used are outlined in IEEE Std. 344 [1]. Occasionally, the equipment fails the testing not remaining functional, forcing another selection of equipment to be made, which causes project delays, cost overruns and numerous other maladies.

The uninterruptible power supply (UPS) for the project was procured as a commercial unit without history of seismic testing or qualification. The intent of this testing was to seismically test the suitability of the unit by the use of a triaxial shake table which would actually impose movement of the type and magnitude of a scaled design basis earthquake (DBE). The unit being tested had been run through several successful 30 second shake table tests with no problems or lack of performance. What ensued at the time of beginning another 30 second test could possibly threaten the seismic qualification and have a negative impact on the project schedule and cost.

\section{THE EVENT}

The UPS unit was allowed to warm up to stabilize the temperature measurements and it was functionally tested according to the manufacturer's factory test plan prior to any seismic testing. These tests were successfully completed, so the unit was ready for the seismic testing to begin. Three single axis sine sweep tests @ $0.2 \mathrm{~g}$ (gravitational force) were performed and data was recorded. The UPS was not powered up at the time.

The UPS unit was again powered up and allowed to stabilize for an hour before running any tests. The shake table (earthquake) tests were started to demonstrate the capability of the unit to withstand a typical earthquake. Two Operational Basis Earthquake (OBE) Tests at 50\% Required Response Spectra (RRS) and one test at $110 \%$ of RRS were successfully completed [1]. Shortly after beginning a second $110 \%$ test, a "Blue Flash" was observed, and the test was immediately suspended. All power to the unit was disconnected and the equipment was verified safe for visual inspection. At this point, the initial investigation into the cause of the flash was begun.

\section{INITIAL CAUSE SPECULATION}

The first order of business was to determine the cause of the arcing flash, which occurred while preparing to run an additional seismic test on the UPS. A capacitor in the UPS discharged to ground (flashed) and the unit shut down automatically, minimizing damage to the unit. A potential setback to the testing and project schedule loomed, if there was a significant design deficiency, requiring another supplier selection and the whole qualification process again on different equipment. A visual inspection with photographs was performed on the UPS unit to document the effects of the flash.

We inspected the equipment for any loose structural connections and none were found. We also summoned a representative from the manufacturer to review the unit and also repair or replace any damaged components. The manufacturer's technician disassembled the inverter unit to ascertain 
which components may have been damaged. It was proposed that some small piece of debris fell into the terminal area of the capacitor causing it to discharge.

\section{INITIAL INVESTIGATION}

Though initial indications pointed to a capacitor failure, no evidence of electrical failure or any mechanical damage to any of the four large capacitors in the assembly could be found. The terminal screw and the bus bar assembly at the location shown in Fig. 1 were burnt with metal melting where the capacitor had discharged. There were no other obvious indications of damage at any other location. Due to the narrow confines of the damage, it was proposed that some small piece of debris fell into the terminal area of the capacitor causing it to discharge. Due to the intense heat, no loose remains of the item of debris could be found. No loose or missing fasteners were observed upon inspection of them.

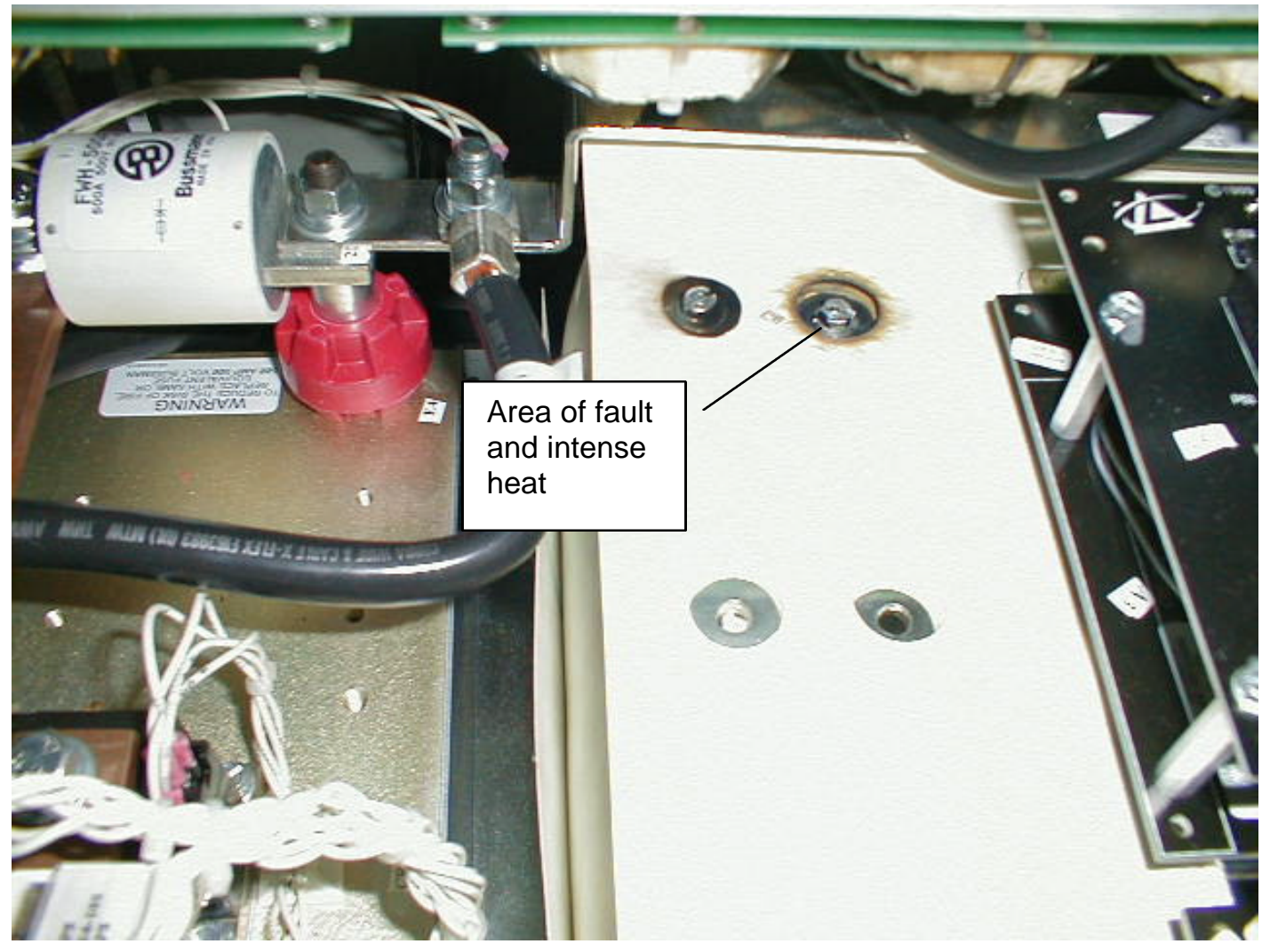

Fig. 1 Initial view of arc flash area

Additional photographs were taken and the old inverter unit was disassembled to its component parts for further investigation (Fig. 2 - 4).

\section{MATERIAL CHARACTERIZATION}

At this time it was determined that in order to support or refute the proposed cause of falling debris, a material characterization study would be performed by a laboratory specializing in that activity. This study would show that if foreign debris were actually responsible for the flash, material of a different composition than the inverter assembly bus or connection would be present in the fault area. The Materials Laboratory of the University of Cincinnati's Materials Sci- ence and Engineering Department was selected to perform the material characterization study.

Procurement arrangements were made with the University to conduct the necessary testing using a scanning electron microscope (SEM). Due to the size limitations of the SEM used for this study, a small section of the inverter bus assembly needed to be cut out for testing purposes. A sample of the charred bus, a "clean" section of bus, the screw terminal that was part of the flash, a "clean" terminal screw, and samples of the insulating paper were bagged for transport to the laboratory. 


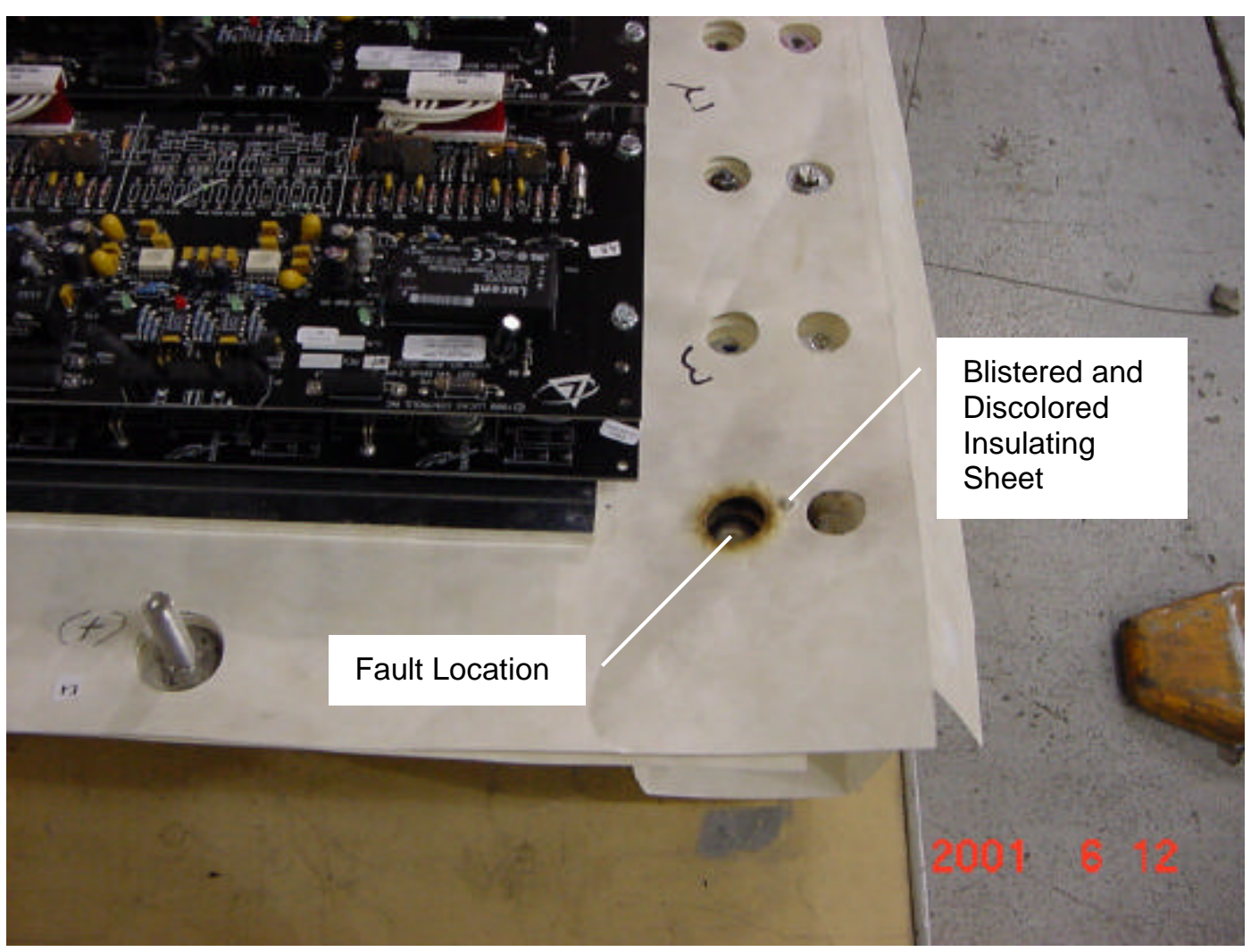

Fig. 2, Unit removed from cabinet

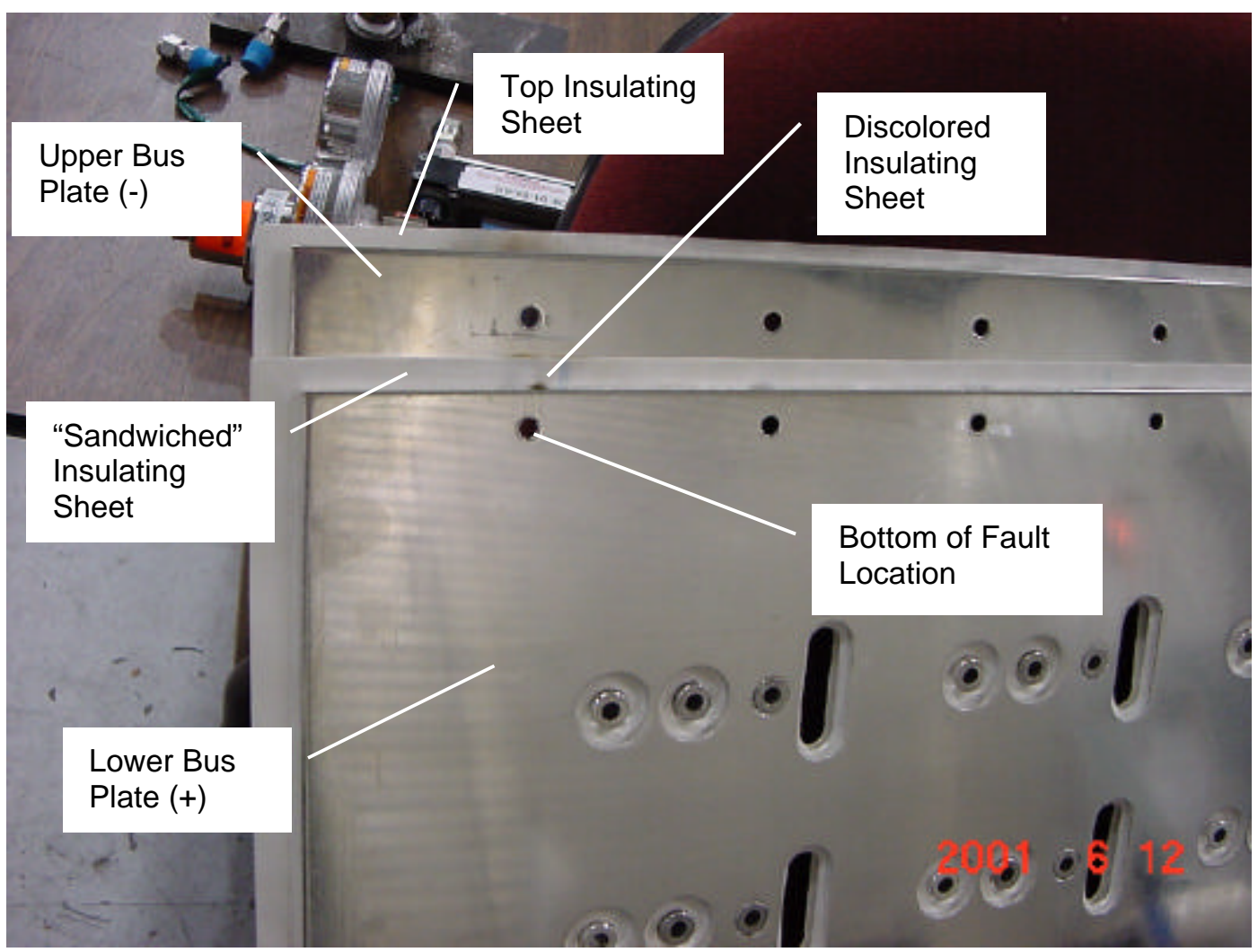

Fig. 3, Disassembled capacitor plate 


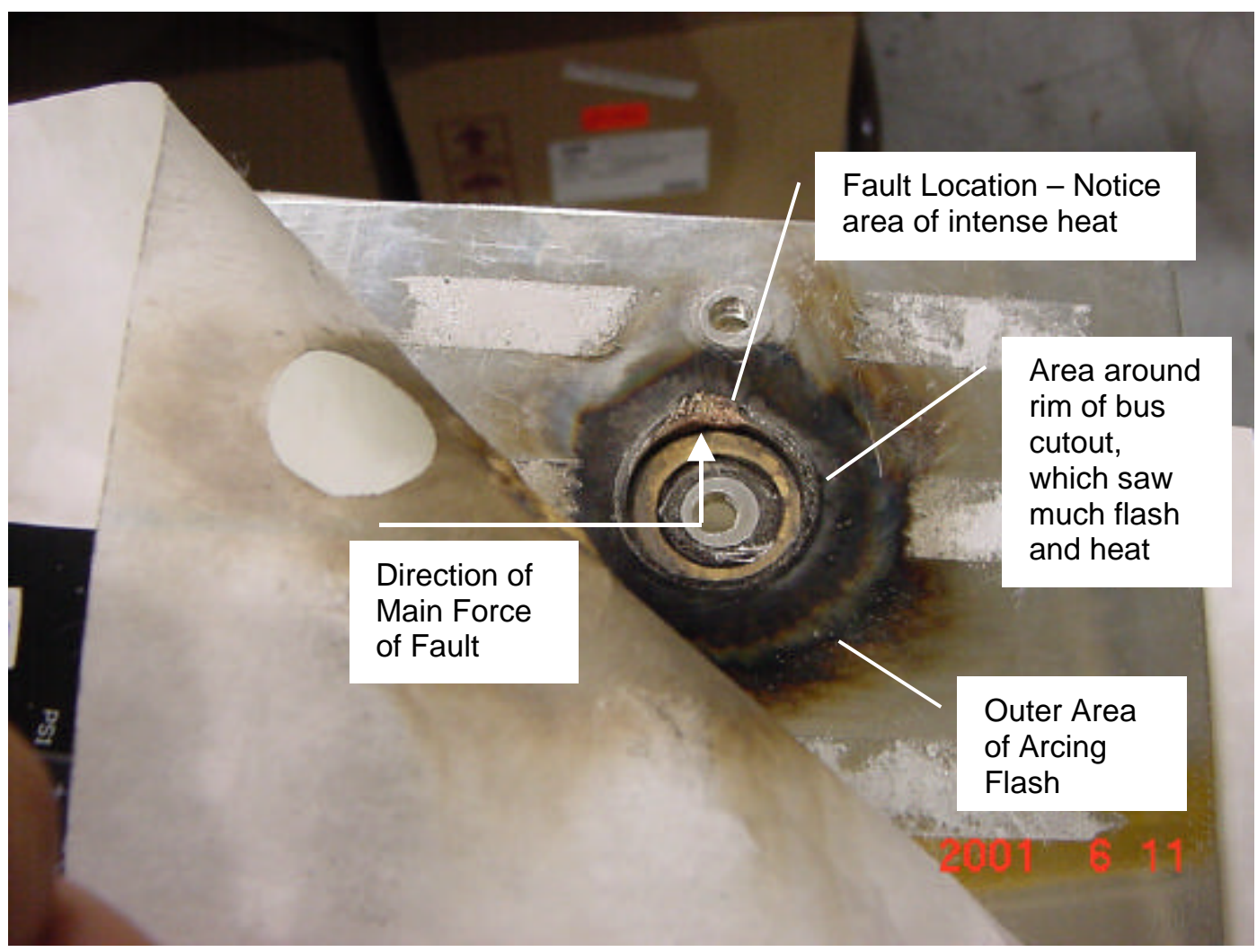

Fig. 4, Fault area uncovered

The samples were taken to the University of Cincinnati laboratory and the search for the "foreign" material began (Fig. 5).

The University of Cincinnati laboratory technician ran several tests on samples of bus, insulation paper, and screws to determine if any foreign material residues were present. We were looking for anything that might indicate that the fault was caused by a piece of debris, which was shaken down into the terminal location. It was found that material deposited on the screw head involved in the flash was something other than the screw material and different than any bus material present. The material had been "welded" by the DC arc and a puddle was left attached to the screw head in the slot area. Fig. 6 shows a simulated reconstruction of the screw and bus assembly, as it would have been at the time of the arc.

Fig. 7 shows the scanning electron microscopy photo of the screw head involved in the flash. The material in the "pool" was characterized as an iron with some trace of manganese, but differed from the chromium/zinc/steel of the screw itself. Fig. 8 and Fig. 9 indicate the differences of the two materials.

The principal of a scanning electron microscope functions by scanning a finely focused beam of electrons onto a sample from which measurable electron energies can be produced. These energies are analyzed by a microprocessor that creates a spectrum of the unique elements that exist in the sample analyzed. It is this series of electrons, which are deflected by collisions with the samples electrons, that indicates the molecular make up of the material [2]. Fig. 8 and Fig. 9 are examples of these spectra and formed the basis of our conclusion that the arc flash was caused by "foreign" material and not an equipment design deficiency.

\section{CONCLUSION}

Based on the results presented, it is conclusive that some metallic debris was dislodged during seismic testing and fell into the capacitor terminal area causing the capacitor to discharge. The evidence of arcing and "welding" of a material foreign to the screw and bus material supports the initial proposed scenario. It was not intended to expend the resources that would be required to determine the exact source of the debris, but to simply determine that it was external to the bus assembly and termination point.

By the material characterization performed, it was demonstrated that a material foreign to either the bus assembly or the screw connection for the capacitor was responsible for the arcing flash. This determination provided the project 
with the assurance that the equipment design was adequate and that a search for another equipment source was not necessary. By ruling out any equipment design problems, the seismic testing and qualification of the UPS unit could continue and the project schedule could be maintained. All testing was completed with satisfactory results and the unit was installed without incident.
As an interim measure, we determined that a remote possibility existed that some other "foreign" material could make its way into the capacitor/plate connection area and fashioned a insulating cover from the same material used in the fabrication of the plate assembly. This "fix" worked well as there were no additional mishaps or setbacks to the testing program.

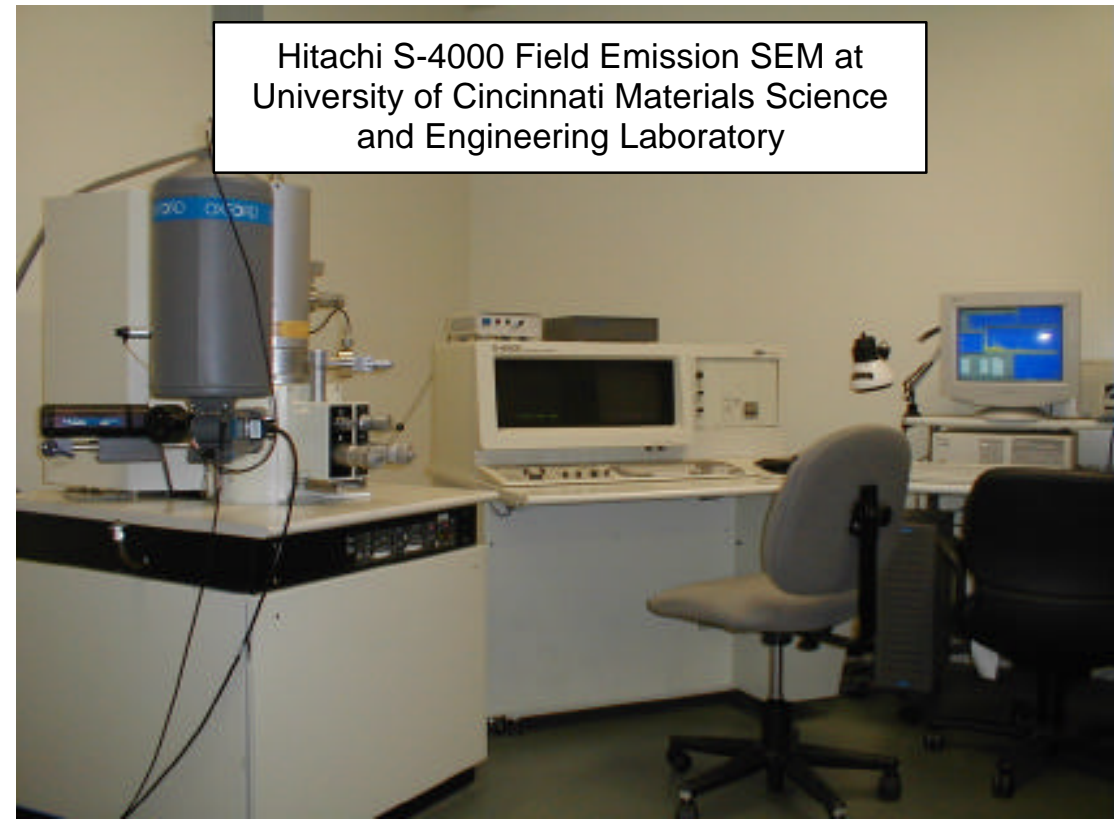

Fig. 5, Scanning electron microscope at University of Cincinnati

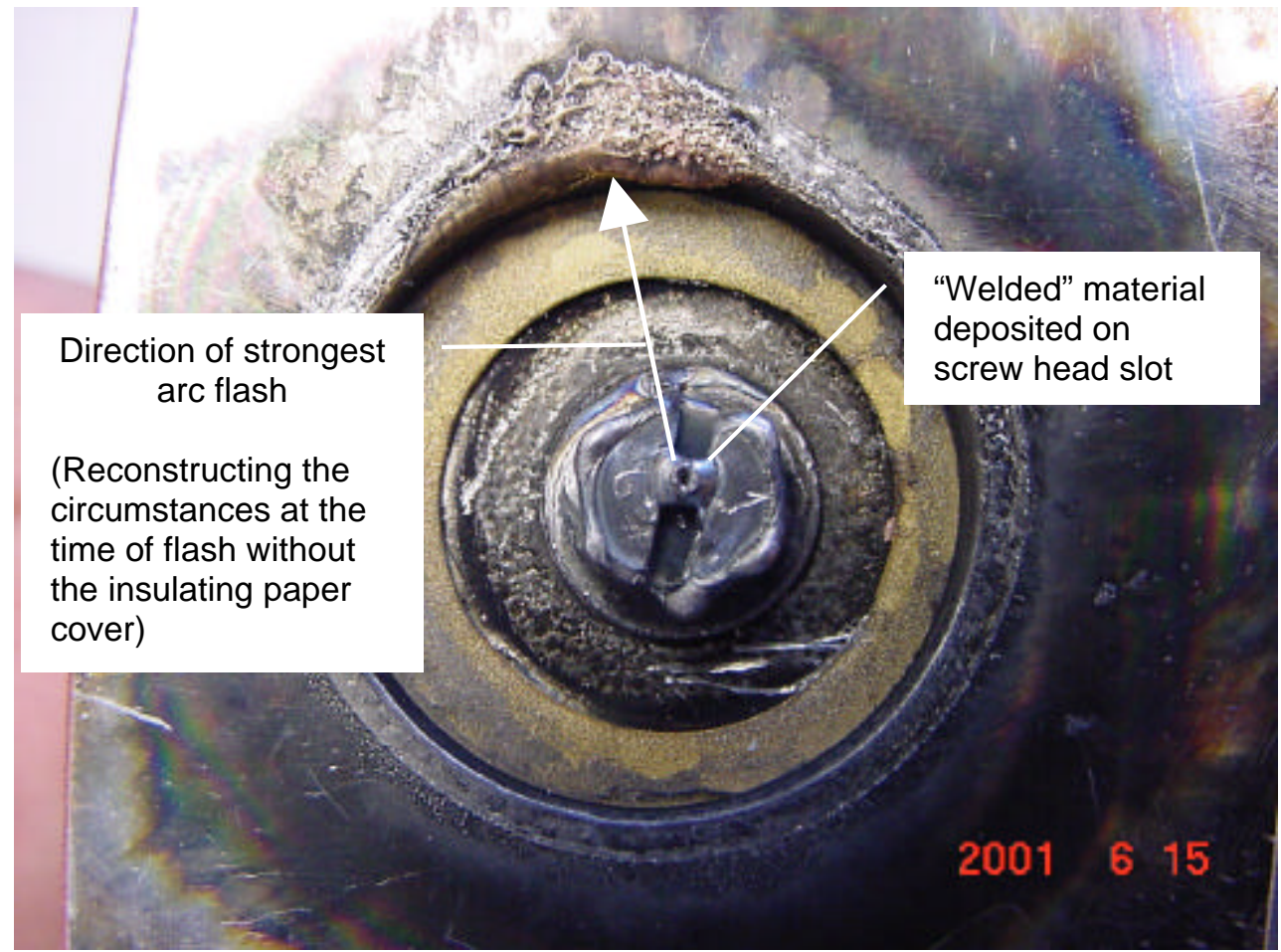

Fig. 6, Reconstructed view of screw head and plate assembly 


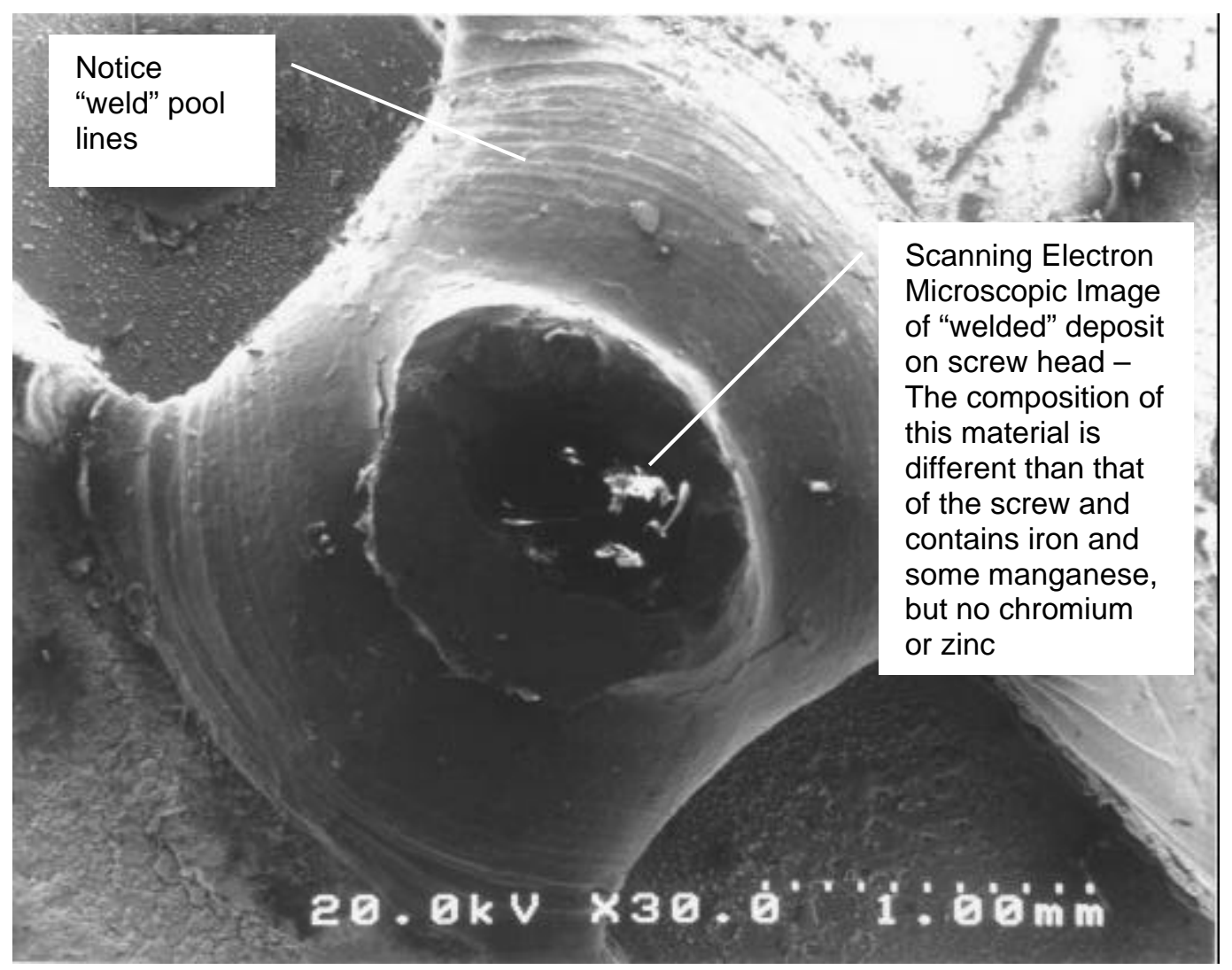

Fig. 7, Scanning Electron Microscope photo of screw head

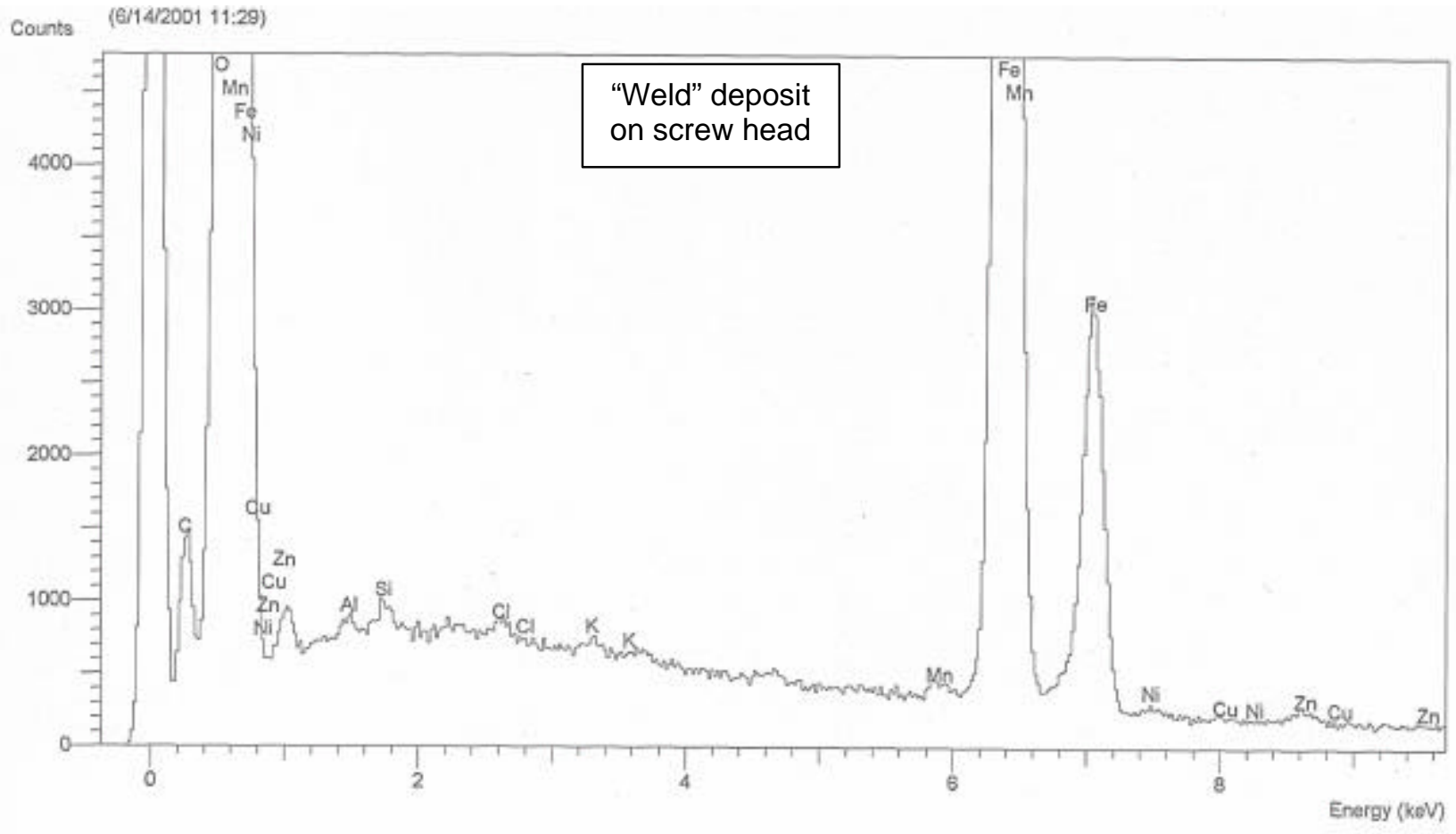

Fig. 8, SEM printout of screw head with "foreign" material 


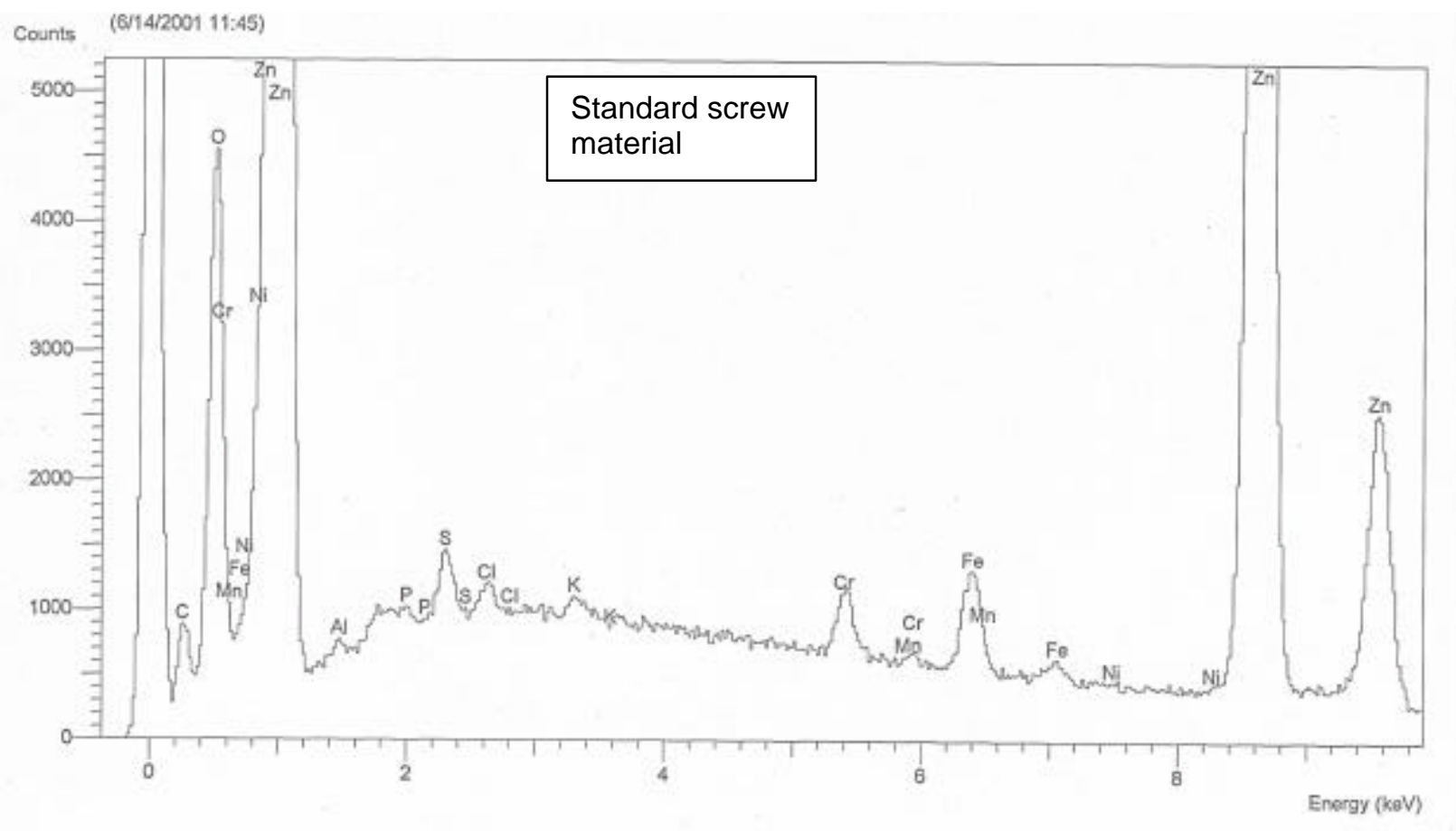

Fig. 9, SEM printout of standard screw head

\section{REFERENCES}

[1] IEEE Recommended Practice for Seismic Qualification of Class 1E Equipment for Nuclear Power Generating Stations, IEEE Std. 3441987.

[2] M. V. Martinez, "A Basic Understanding of Scanning Electron Microscopy (SEM) and Energy Dispersive X-ray Detection (EDX)", Available: http://www.forensicevidence.net/iama/sem-edxtheory.html

\section{ACKNOWLEDGMENTS}

The information contained in this paper was developed by Westinghouse Savannah River Company/Bechtel Savannah River, Inc. under DOE Contract DE-AC09-96SR18500. 